\title{
O estágio em língua inglesa e o desafio decolonial: problematizações sobre as relações interpessoais de seus/suas agentes
}

The English teaching practicum and the decolonial challenge: problematizing its agents' interpersonal relationships

\author{
Julma Dalva Vilarinho Pereira BORELLI ${ }^{1 *}$ \\ Universidade Federal de Mato Grosso (UFMT) \\ Rosane Rocha PESSOA ${ }^{2 * *}$ \\ Universidade Federal de Goiás (UFG)
}

\begin{abstract}
RESUMO: As discussões deste artigo são parte de um estudo qualitativo (DENZIN; LINCOLN, 2013) e têm como foco as relações interpessoais desenvolvidas durante o estágio em língua inglesa no curso de Letras. Nosso objetivo é ampliar as possibilidades de pensar as relações que são construídas nessa experiência que envolve a universidade e a escola na formação dos/as professores/as licenciandos/as. Sendo assim, as discussões foram desenvolvidas com professores/as de escolas públicas, professores/as licenciandos/as e professores/as de universidades públicas da região Centro-Oeste. Esses olhares sobre as relações desenvolvidas no estágio ressaltam a falta de trabalho conjunto, a hierarquização de saberes e os conflitos que são vivenciados em um estágio que é planejado na universidade, sem negociação com a escola. O desafio de olhar para essas relações amparadas no pensamento decolonial nos ajuda a reconhecer e, ao mesmo tempo, a confrontar o privilégio historicamente atribuído aos saberes acadêmicos em busca de práticas mais igualitárias.
\end{abstract}

PALAVRAS-CHAVE: Estágio em Língua Inglesa. Pensamento decolonial. Formação de professores/as de inglês.

ABSTRACT: The discussions presented in this article are part of a qualitative study (DENZIN; LINCOLN, 2013) and focus on the interpersonal relationships developed in the English

\footnotetext{
" Doutora em Letras e Linguística pela Universidade Federal de Goiás. Atua como professora de Estágio Supervisionado de Inglês no Departamento de Letras da Universidade Federal de Mato Grosso, campus de Rondonópolis. E-mail: julmaborelli@gmail.com.

*** Doutora em Linguística Aplicada pela Universidade Federal de Minas Gerais. Atua como professora de Inglês no Departamento de Línguas Estrangeiras da Universidade Federal de Goiás. E-mail: pessoarosane@gmail.com.
} 
teaching practicum in the course of Letras. Our aim is to expand the possibilities of thinking about the relationships that are built in this experience that involves the university and the school in the pre-service teacher education. Thus, the discussions were developed with public school teachers, pre-service teachers and teachers from public universities from the Midwest region of Brazil. Their views on the relationships established in the teaching practicum raised problematizations concerning the lack of collaborative work, the hierarchization of knowledge and the conflicts of a teaching practicum which is planned in the university without negotiation with the school agents. The challenge of looking at these relationships grounded on decolonial thinking helps us to recognize and at the same time confront the privilege historically ascribed to academic knowledge in search of more egalitarian practices.

KEYWORDS: English teaching practicum. Decolonial thinking. English teacher education.

No mundo há muito para aprender com aqueles outros que a modernidade tornou invisiveis.

(MALDONADO-TORRES, 2010, p. 437)

Conforme temos discutido em alguns trabalhos (BORELLI, 2018a; 2018b; PESSOA; BORELLI; SILVESTRE, no prelo), o estágio é um importante momento na formação de professores/as de inglês. Dentre os seus desafios, o estágio pressupõe a saída da universidade para buscar os saberes construídos e mobilizados no ambiente escolar. É nesse encontro com professores/as e estudantes da escola que nós, professores/as da universidade, e nossos/as professores/as licenciandos/as construímos o conhecimento que embasa as nossas reflexões nos dois últimos anos da graduação.

Tendo em vista a relevância do estágio e as expectativas e inseguranças que permeiam esse período, nos dedicamos, neste artigo, a discutir as relações interpessoais estabelecidas por professores/as da universidade (PU), professores/as da escola (PE) e professores/as licenciandos/as (PL). As conversas estabelecidas com esses três grupos nos fazem considerar que um ponto crucial para que possamos ressignificar o estágio consiste em decolonizar as relações interpessoais vivenciadas. Optamos por abordar as relações interpessoais por serem fortemente marcadas pelas subjetividades dos/as participantes que vêm de locais diferentes, seja da universidade ou da escola, e esse local de pertencimento, segundo a interpretação que desenvolvemos, interfere significativamente nas relações que são, ou não, construídas. 
Uma das justificativas para voltarmos nosso olhar para as relações estabelecidas durante o período de estágio encontra respaldo na citação que apresentamos na epígrafe deste artigo. Realmente, "há muito para aprender com aqueles outros que a modernidade tornou invisíveis" (MALDONADO-TORRES, 2010, p. 437). Se pensarmos na universidade como local de reprodução dessa lógica de colonialidade, a outra justificativa assenta-se no reconhecimento de que os saberes que são produzidos nesse local não podem mais estar alheios à vida real das pessoas, e nós, professores/as e pesquisadores/as, precisamos nos engajar em projetos que nos permitam repensar nossas práticas, questionando as concepções e os valores que reproduzem.

É importante que possamos refletir sobre a forma de vida inventada para atender aos intuitos de colonialidade e nos lembrar que esse "é um sistema de desigualdade e privilégio que se move ao longo do tempo, reivindica espaços geográficos, e é perpetuado por meio de práticas epistêmicas materiais e discursivas em espaços sociais e institucionais" (KERR, 2014, p. 88). Sendo o conhecimento um dos meios utilizados para o estabelecimento de relações de poder e hierarquização, o conhecimento científico é, então, instituído como sendo superior às outras formas de conhecimento (LANDER, 2005). Dessa forma, a universidade, que se estabelece como a principal instituição produtora do saber científico, torna-se um importante local de reprodução dessas "práticas epistêmicas materiais e discursivas" que contribuem para manter as colonialidades.

Pensando o processo de construção de conhecimento, Mignolo (2009, p. 18) faz a seguinte consideração acerca dos papéis exercidos pelas instituições:

\footnotetext{
Tomando um atalho das condições gerais de produção de conhecimento entre os seres humanos sensu largo (isso é, sem normatividade de raça e de gênero/sexo) para a produção de conhecimento na organização da sociedade, são criadas instituições que cumprem duas funções: o treinamento de novos membros (epistemicamente obedientes) e o controle de quem entra e de que produção de conhecimento é permitida, rejeitada, desvalorizada ou celebrada.
}

A fala de Mignolo (2009) ilustra de que forma, por exemplo, os critérios de cientificidade - objetividade, neutralidade - têm legitimado saberes e invisibilizado outras formas de conhecimento. Sendo assim, vale repensar que tipo de profissionais a nossa formação, que culmina no estágio, tem contribuído para formar; que saberes estão 
sendo priorizados e levados em conta em nossas práticas; e que valores estamos reproduzindo ou desafiando por meio de nossas ações?

Para que possamos desenvolver as reflexões propostas neste artigo, iniciamos com a apresentação dos saberes que compõem este estudo, explicitando nosso caminho metodológico. Em seguida, discutimos o estágio e o desafio de vivenciá-lo como um projeto decolonial. Tendo em vista o nosso foco de problematizar as relações, desenvolvemos a discussão do estágio tratando das relações entre professores/as licenciandos/as e professores/as da escola, entre professores/as licenciandos/as e professores da universidade e, por fim, entre professores/as da escola e professores/as da universidade. Dessa forma, buscamos diferentes saberes que possam ampliar nossos olhares para o estágio na formação de professores/as de inglês.

\section{Os saberes deste estudo}

Os saberes que compõem este artigo foram compartilhados em reflexões que fazem parte da tese $O$ estágio e o desafio decolonial: (des)construindo sentidos sobre a formação de professores/as de inglês (BORELLI, 2018b). Trata-se de uma pesquisa qualitativa (DENZIN; LINCOLN, 2013) que leva em conta aspectos de uma prática decolonial. Dentre as definições de pesquisa qualitativa, Denzin e Lincoln (2013, p. 7) acrescentam que os/as pesquisadores/as dessa linha "tentam fazer sentido ou interpretar um fenômeno a partir dos significados que as pessoas atribuem a ele". Nesse intuito, a construção de possíveis sentidos acerca das relações construídas no estágio tem como base as concepções de seus/suas agentes. São elas que embasam as interpretações e a discussões que apresentamos.

Um de nossos intuitos era desenvolver as reflexões sobre o estágio com participantes - professores/as de universidades públicas, professores/as de escolas públicas e professores/as licenciandos/as de universidades públicas - que atuassem na região Centro-Oeste. Além de trabalharmos em universidades que ficam nessa região, acreditamos na importância não apenas de problematizar, mas também de visibilizar as práticas desenvolvidas nesse local. Após os contatos e convites para integrar o trabalho, contamos com a participação de 10 professores/as de universidades públicas, 11 professores/as de escolas públicas que já haviam trabalhado com estágio e 40 
professores/as licenciandos/as, também de universidades públicas. Os locais de atuação dos/as professores/as da universidade são: Distrito Federal (DF1), quatro cidades de Goiás (GO1, GO2, GO3 e GO4), uma cidade Mato Grosso do Sul (MS1), e três cidades de Mato Grosso (MT1, MT2 e MT3). Os locais de atuação dos/as professores/as da escola são: 8 atuam em uma cidade de Goiás (GO4) e 3 em uma cidade do Mato Grosso (MT1). Por fim, os/as professores/as licenciandos/as participantes são de quatro universidades: uma no Distrito Federal (DF1), uma em Mato Grosso (MT1) e duas em Goiás (GO1 e GO4).

Os/As professores/as da universidade (PU) e da escola (PE) conversaram e puderam refletir sobre as perguntas propostas individualmente, e essas conversas foram gravadas em áudio. As conversas com os/as professores/as licenciandos/as também foram gravadas em áudio, porém foram conduzidas coletivamente com os grupos de professores/as licenciandos/as dos últimos períodos do curso de Letras (Inglês/Português-Inglês) de cada universidade. Foram essas conversas que nos permitiram ampliar nossos olhares sobre o estágio, na busca por vivenciarmos relações pautadas pelo pensamento decolonial.

\section{O estágio e o desafio decolonial}

Olhar para o estágio tendo em vista o pensamento decolonial nos ajuda a reconhecer a universidade como uma importante instituição de reprodução de práticas de colonialidade. Acerca do privilégio atribuído ao conhecimento científico, CastroGómez (2007, p. 81, grifos no original) afirma que a universidade não apenas produz o conhecimento válido, mas também "estabelece as fronteiras entre o conhecimento útil e o inútil, entre a doxa e a episteme, entre o conhecimento legítimo (quer dizer, o que goza de 'validade científica') e o conhecimento ilegítimo". Neste trabalho, ampliamos essa reflexão para problematizar de que forma essa superioridade conferida à universidade, produtora e guardiã do conhecimento legitimado, traço de uma organização colonial/moderna, afeta o estágio, no que diz respeito às relações que (não) se estabelecem entre universidade e escola na formação dos/as futuros/as professores/as de inglês. 
Retomando os conceitos de colonialidades que embasam nossas reflexões, sabemos que a colonialidade do poder tem como base, principalmente, a ideia de raça e o papel que as pessoas ocupam na organização do trabalho (QUIJANO, 2005; 2010). Se considerarmos que tanto na escola quanto na universidade estamos diante de professores/as, vemos que um dos fatores responsáveis por justificar a hierarquização estabelecida entre os/as professores/as é o espaço que ocupam nessa organização do trabalho - universidade ou escola.

Muitos estudos têm enfatizado essa separação (ZEICHNER, 2010; LÜDKE; BOING, 2012; GATTI, 2014) e reconhecem que "[u]m problema perene em programas tradicionais de formação de professores mantidos por faculdades e universidades tem sido a falta de conexão entre os cursos de formação de professores nessas unidades e o campo da prática" (ZEICHNER, 2010, p. 483-484). No caminho que adotamos neste trabalho, não basta haver essa conexão, antes precisamos de uma ressignificação epistemológica que possibilite uma revisão dos muitos papéis que podem ser vivenciados por todos/as os/as participantes no estágio.

Se, por um lado, temos uma maior valorização atribuída ao saber acadêmico, vemos que, por outro, essa superioridade é utilizada como justificativa para a sua ineficiência no contexto escolar. Como forma de resistência, é comum ouvirmos de professores/as da escola que os saberes da universidade não servem para a escola. Da mesma forma, professores/as da universidade deixam de se aproximar do contexto escolar por desacreditar que ali seja um espaço de conhecimento. Isso dificulta o envolvimento e a construção de uma relação de maior integração entre os/as participantes do estágio. A esse respeito, Walsh (2009) retoma o conceito de colonialidade do saber (LANDER, 2005), gerado pelo privilégio dos saberes eurocêntricos. Vencer esse binarismo e compreender ambos os locais como produtores de saberes é um desafio que temos até os dias de hoje.

Por fim, além de pensar essa hierarquia em termos dessas duas colonialidades, problematizamos também o fato de que os/as professores/as do contexto escolar são, muitas vezes, afastados/as da possibilidade de produção de conhecimento por estarem distanciados/as da universidade e por entendermos como produção de conhecimento apenas o modelo legitimado pela academia. Essa separação do indivíduo da capacidade cognitiva de produção de conhecimento nos remete à colonialidade do ser 
(MALDONADO-TORRES, 2007), em que grupos eram julgados como menos capazes por não terem os seus saberes e práticas legitimados.

Como forma de desafiar esse modelo epistêmico, o pensamento decolonial advoga por um conhecimento geo e corpo-politicamente localizado, ou seja, importam igualmente o local de produção daquele conhecimento, assim como aquele/a que o produz. Conforme Mignolo (2012, p. 14), "a geo e corpo-políticas criaram as condições para muitos se desprenderem, escaparem da gaiola de ferro do 'conhecimento absoluto' imperial". Essa abertura permite não apenas desafiar a suposta universalidade do conhecimento hegemônico, como também reconhecer seu local de produção e questionar os interesses a que serve.

Tendo em mente essas relações de colonialidade, voltamos nossos olhares para tantos outros saberes. São as diferentes perspectivas, representadas por esses saberes corpo-politicamente localizados, que nos permitem tecer considerações acerca dessa lógica de colonialidades que ainda pode orientar, e em alguns aspectos definir, o tipo de relação que se estabelece entre universidade e escola, possibilitada pelo estágio.

\subsection{As relações entre os/as professores/as licenciandos/as e os/as professores/as da escola}

Iniciamos a discussão das relações interpessoais do estágio tomando por base as perspectivas dos/as professores/as licenciandos/as e dos/as professores/as da escola, buscando discuti-las decolonialmente. Acerca dessas relações, Silva (2002, p. 79) argumenta que nosso processo de construção de identidades docentes é "uma história de relações com outros", e o estágio é um momento em que essas relações são ampliadas, incluindo professores/as e alunos/as da escola. Considerando o que discutimos até agora e tendo em vista que o estágio ocorre, por vezes, sem que a universidade e a escola estejam unidas nesse projeto, podemos pensar que a relação com o/a professor/a da escola acabe por constituir mais um desafio para os/as professores/as licenciados/as. Além disso, sem que estejam engajados/as em um trabalho conjunto com os/as professores/as da universidade, os/as professores/as da escola podem não se envolver, deixando de atuar como mais um/a formador/a nesse processo.

Dentre os temas que foram abordados em nossas conversas, os/as professores/as da escola apontam as dificuldades que são causadas pela pouca experiência do/a 
professor/a licenciando/a, pela falta de preparação para a chegada ao contexto escolar, ou mesmo pela falta de conhecimento das dinâmicas desse espaço. Esses fatores podem gerar conflitos que acabam por impedir um maior compartilhamento de conhecimentos entre eles/as:

\begin{abstract}
O primeiro impacto que eu percebi é que o estagiário vem com um olhar para o professor e depois ele fala: "ah, esse professor é muito ruim, ele não sabe dar aula". Então eu penso que foi um choque, para mim o primeiro choque. [...] Quando a gente sentou, que ela foi falar, ela não chegou e falou olha, Jacy, você faz assim, olha... Não. Ah, você não dá conta disso, você não consegue isso, e isso aqui? [...] Então eu não achei legal essa invasão. Foi assim que eu me senti, invadida. [...] Na regência, eu já estava meio assim, não muito amável com a situação. [...] A gente não teve um relacionamento ruim, eu fiquei mais retraída diante do feedback. (JACY, PE, GO4)
\end{abstract}

Para mim foi bem tranquilo [receber estagiários/as] porque eu tenho firmeza naquilo que eu estou fazendo. Eu vejo que os professores têm certo receio de receber esses estagiários na regência. E eles não são de tudo culpados por ter esse receio, porque nós já tivemos várias situações de problemas. De estagiários que não conseguem ver o todo e aí acabam analisando só uma parte daquela aula, uma situação esporádica. (PATRÍCIA, PE, MT1)

No relato de Jacy (PE, GO4), vemos a postura desrespeitosa de uma professora licencianda que, após o estágio de observação, avalia o trabalho da professora da escola. Precisamos preparar o/a professor/a licenciando/a para ir até a escola aprender com os/as professores de lá, o que novamente requer uma ressignificação epistemológica, e iniciar uma discussão ética na universidade de respeito e cuidado com os/as professores/as que aceitam participar do estágio como formadores/as no ambiente escolar. Da mesma forma, o/a professor/a da escola precisa estar mais seguro/a de seu papel para que não se submeta a esse tipo de situação em que há, na verdade, uma inversão de papéis entre aqueles/as que, em uma estrutura tradicional de estágio, avaliariam ou seriam avaliados/as. Podemos pensar que uma postura avaliativa de todos/as os/as participantes seria o encaminhamento de um estágio em que relações fossem mais horizontalizadas, mas esse tipo de interação precisa ser pautado no respeito mútuo. Mais uma vez, essas posturas podem ser pensadas como exemplos da hierarquização dos saberes desses dois espaços.

Ao tratar do conhecimento no contexto de colonialidade, Grosfoguel (2010, p. 478) argumenta:

A pretensa superioridade do saber europeu nas mais diversas áreas da vida foi um importante aspecto da colonialidade do poder no sistema-mundo 
colonial/moderno. Os saberes subalternos foram excluídos, omitidos, silenciados e/ou ignorados.

No caso do estágio, "a pretensa superioridade do saber" da universidade acaba servindo para autorizar o/a professor/a licenciando/a a depreciar a prática de uma professora da escola, com quem deveria aprender durante o estágio. Se levarmos em conta que, devido ao conhecimento construído na universidade, é quase inevitável, e até desejável, que o/a professor/a licenciando/a chegue ao contexto de estágio com um olhar crítico ${ }^{3}$, devemos considerar também que essa mesma criticidade deve prezar por uma postura de respeito e cuidado com o/a professor/a da escola que o/a recebe.

Além dessa "superioridade" dos conhecimentos da universidade, temos ainda que considerar o fato de que, muitas vezes, a representação que se tem do/a professor/a da escola na universidade é a de alguém que precisa expandir seus conhecimentos, que tenha mais a aprender com a universidade do que a ensinar. Retomando a fala de Jacy (PE, GO4), quando essa professora diz que o olhar da universidade para a escola pública é "medíocre", isso inclui o olhar que voltamos para os/as professores/as que atuam nesse espaço e para os saberes que ali são construídos. Isso faz com que o estágio seja uma prática contraditória: por que enviamos nossos/as professores/as licenciandos/as para a escola se não acreditamos no que podem aprender com os/as professores/as desse espaço? De certa forma, isso reduz a atividade a um mero cumprimento de burocracias.

Situações como essa justificam o "receio", mencionado por Jacy (PE, GO4) e Patrícia (PE, MT1), que alguns/mas professores/as da escola têm ao receber aqueles/as que vêm da universidade. Tomando por exemplo a situação vivida por Jacy (PE, GO4), ela complementa dizendo o seguinte acerca da experiência de receber uma professora licencianda:

Primeiramente, não querer nunca mais um estagiário na minha sala. Horrível, né? Mas eu abriria. Eu estou dizendo que naquele ano eu recusei um [estagiário] depois. Porque eu achei que não foi uma experiência boa. E muitos outros colegas falavam a mesma coisa.

3 "Crítico", nesse contexto, tem o sentido de problematizador, como utilizado na Linguística Aplicada Crítica. 
Diante dessa discussão, voltamos às considerações acerca da motivação dos/as professores/as da escola para atuar no estágio. A pouca ou nenhuma relação entre a universidade e a escola, em momentos de planejamento do estágio, faz com que o/a professor/a da escola tenha dúvidas sobre que papéis poderia vivenciar no estágio. Nas conversas coletivas realizadas com os/as professores/as licenciandos/as, esse tema é retomado e discutido por alguns/mas participantes: A professora [da escola] confessou pra gente, a gente foi conversar com ela e
ela disse que não entendia muito bem como funcionava. Então eu estava
pensando, "será que eu estava fazendo certo?", "o que eles estão olhando
aqui na aula, sabe?," [...] A universidade precisa fazer o estágio mais efetivo,
O professor [da escola] precisa saber o que a gente precisa fazer. [...] É
diferente quando o estagiário ou a universidade conversam com o professor.
(BEL, PL, GO4)

Uma coisa que falta no estágio é conversa. Não tem diálogo no estágio. Do professor daqui com a gente. Do professor daqui com a escola, não tem diálogo nenhum. [...] Diálogo eu tive no [cita outra experiência] e eu aprendi muito. É nessas horas que a gente aprende. Nas conversas, as coisas fazem sentido. (TENNESSEE, PL, GO4)

Observando os relatos, vemos que essa é uma queixa local, apresentada pelos/as professores/as licenciandos/as da região identificada por GO4. Esses/as participantes apresentaram importantes apontamentos críticos e seus relatos enfatizam a falta de diálogo que acontece no estágio em diferentes âmbitos.

Em uma interpretação decolonial, não é apenas o diálogo que precisa ser estabelecido, mas, como temos visto, um diálogo mais horizontalizado, que valorize outros saberes que possam dar sentidos ao estágio para os/as que dele participam. O surgimento desse tema durante nossa conversa foi impulsionado pelas dificuldades que os/as professores/as licenciandos/as vivenciam durante o estágio. Nesse caso, não apenas os/as licenciandos de GO4 relatam ter vivido dificuldades para explicar o que estavam fazendo naquele momento na escola:

Quando foi no Estágio 3, na época da semirregência, quando eu cheguei na escola o professor tinha saído de licença. E aí veio a professora substituta que inclusive era minha amiga, que já tinha dado aula lá. E eu dava aula de inglês para ela, particular, em casa. O nível dela era mínimo, aí as aulas dela ficaram praticamente na minha mão. Eu não passei pela semirregência, de sentar com o professor e entender. Eu não passei. Eu tive que pegar todas as turmas da escola. (MEL, PL, GO4)

Quando eu cheguei no terceiro estágio, eu fui na primeira aula e eles já queriam me colocar dentro de sala para dar aula porque esse professor não 
tinha ido. Eu falei assim, não, eu não posso dar aula agora, que o meu [estágio] é semirregência. Mas acabou que eu dei duas regências inteiras lá porque ele não foi. [...] Então, é como a Bel falou, acho que se tivesse um contato aqui da faculdade com a escola, acho que isso não teria acontecido. (JÉSSICA, PL, GO4)

Eu fiz regência na mesma escola, com a mesma professora que eu fiz a observação. Quando eu fui fazer o estágio de regência, que eu fui lá para conversar com a professora, ela falou que liberaria, só que eu teria que pegar todas as aulas dela. E eu falei que não posso porque eu tenho aula de manhã, tenho outros compromissos. (CARLA, PL, MT1)

Nesses relatos, temos algumas implicações do distanciamento entre a universidade e a escola. Sem participar do planejamento do estágio, os/as professores/as da escola por vezes desconhecem o trabalho que deve ser desempenhado pelos/as professores/as licenciandos/as em cada etapa. Mel (PL, GO4) relata que, no período de semirregência, no qual deveria atuar como auxiliar do/a professor/a da escola, teve "que pegar todas as turmas”. Jéssica (PL, GO4) e Carla (PL, MT1) vivenciaram situações semelhantes: "eu fui na primeira aula e eles já queriam me colocar dentro de sala para dar aula porque esse professor não tinha ido" e "ela falou que liberaria, só que eu teria que pegar todas as aulas dela". Conforme argumentamos, "pegar as aulas" não é o que se espera dos/as professores/as licenciandos/as na etapa de semirregência do estágio.

A falta de diálogo ou da construção colaborativa de um projeto de estágio, acaba por gerar dificuldades para os/as professores/as licenciandos/as que não se sentem prontos para assumir as atividades de ensino e, ao mesmo tempo, não querem deixar de atender à expectativa do/a professor/a da escola. Tais considerações nos fazem refletir que advogar pela decolonialidade, além de se configurar como uma postura política e ética, pode contribuir diretamente para a organização do estágio, assim como para tornálo mais significativo para seus/suas participantes.

\subsection{As relações entre os/as professores/as licenciandos/as e os/as professores/as da universidade}

Um diferencial acerca das relações construídas entre os/as professores/as licenciandos/as e os/as professores/as da universidade reside no fato de estarmos tratando de relações que se estabelecem no ambiente da universidade. Considerando mais amplamente, Furlani (2002, p. 60) ressalta que 
[...] as relações que os estudantes desenvolvem na universidade (com o conhecimento, os professores, os amigos e a instituição) podem provocar alterações no olhar de cada um sobre a profissão, sobre o ensino, sobre a educação, sobre o futuro e sobre si mesmos, construindo outros olhares e gestos, no hoje, no estar-sendo.

Tendo em vista o objetivo de discutir as relações, uma ênfase maior é dada às experiências de estágio que subentendem uma interação que ultrapasse o espaço da universidade, ou seja, que envolva também a escola. Nesse mesmo caminho, em muitas das conversas realizadas para que pudéssemos pensar o estágio, tanto nas individuais quanto nas coletivas, uma considerável atenção foi dada às outras relações, ao passo que as relações entre professores/as licenciandos/as e professores/as da universidade, por vezes, sequer foram mencionadas. Apesar disso, o intuito de olhar mais amplamente para as relações interpessoais do estágio, nos permite reconhecer que as imposições de colonialidades não precisam, necessariamente, de outro espaço para se manifestar; dentro da própria universidade a estrutura de hierarquização é fomentada e reproduzida.

Ao conversarmos sobre suas relações com os/as professores/as licenciandos/as, os/as professores/as da universidade destacam a manutenção de uma boa relação e pouco foi acrescentado a essa informação:

É bem tranquila. Eu sou um professor que, de um modo geral, nunca tenho problema com aluno. (DÁNIE, PU, MT2)

Com relação aos alunos, eu também acho que foi tudo tranquilo. (ANA, PU, MT1)

É, comigo, em geral, a relação é tranquila. (GEISA, PU, DF1)

A gente tem uma relação muito boa. (GIU, PU, GO1)

A minha relação com os alunos, novamente eu toco naquela tecla de turmas reduzidas, de você conseguir se aproximar mais do aluno, de você conseguir uma relação mais próxima, então o acompanhamento fica melhor, na minha opinião. (SEVERO, PU, GO3)

Como vemos nos relatos, o relacionamento com os/as professores/as licenciandos/as não parece apresentar grandes desafios para o/a professor/a da universidade. A disciplina de Estágio Supervisionado, da forma que tem sido desenvolvida na maioria dos casos, não se diferencia significativamente das outras disciplinas do curso. Não havendo aproximação dos/as professores/as da universidade do contexto escolar, sua tarefa se reduz aos encontros que acontecem na universidade, 
em horários de aulas. No entanto, quando temos acesso aos pontos de vista dos/as professores/as licenciandos/as, nos questionamos sobre o que está sendo considerado como uma "boa" relação.

Um apontamento feito pelos/as professores/as licenciandos/as do local, identificado por GO4, acerca da relação que estabelecem com os/as professores/as da universidade, diz respeito ao pouco engajamento desse/a professor/a com as atividades do estágio. Segundo os/as licenciandos/as, uma maior aproximação com os/as professores/as da universidade poderia beneficiá-los/as, prepará-los/as melhor para essa experiência:

O que até hoje eu sinto falta é que o professor do estágio chega aqui, dá as aulas e fala "agora você vai lá, dar as aulas lá", só que você não tem um guia, eu me senti um pouco perdida. (MEL, PL, GO4)

Eu acho que os professores [da universidade] deveriam estar mais próximos dos alunos no estágio. (JÉSSICA, PL, GO4)

E ter um melhor acompanhamento do aluno [professor/a licenciando/a] na escola. (FERNANDA, PL, GO4)

Não tem um acompanhamento do professor [da universidade], como as meninas disseram. A gente vê o que tem que ver aqui na segunda, e na quarta-feira a gente é jogado para a escola. [...] O que é para eu fazer na escola? (TENNESSEE, PL, GO4)

Os/As professores/as licenciandos/as do local, identificado como MT1, não fizeram considerações sobre suas relações com a professora da universidade, deram mais ênfase às relações estabelecidas com os/as professores/as da escola. Pouco foi dito acerca dessas relações também no contexto DF1. Contudo, alguns relatos feitos nesse contexto nos chamaram a atenção por valorizarem justamente o acompanhamento feito pela professora da universidade:

Eu estava muito ansiosa para ter os meus planos de aula avaliados, para fazer os planos de aula e aplicá-los, porque eu sentia que tinha muita dificuldade nisso ainda. E eu acho que tudo aquilo de fazer plano e mandar e receber feedback me ajudou bastante a poder visualizar melhor as aulas, de lá pra cá. (MICHELE, PL, DF1)

A participação efetiva mesmo da [nome da professora da universidade] nos planos, que sempre- [risos]. Foi muito bom ter esse auxílio presente em todo o momento. $\mathrm{O}$ que gerou um conhecimento maior foi essa parte. Durante todo o semestre, eu acho que essa foi a parte que a gente mais evoluiu. Essa parte é a mais prática, pra mim eu vejo como a mais útil. (FLORÊNCIA, PL, DF1) 
Vemos que as participantes valorizam esse acompanhamento feito pela professora da universidade. Florência (PL, DF1) chega a se referir a essa parte como aquela que promoveu maior crescimento. Em geral, há no estágio uma busca e uma expectativa por essa "parte prática" e, segundo os relatos, a orientação e participação da professora da universidade nessa etapa trouxe para a formação um importante diferencial. Essa importância do/a professor/a é corroborada por Furlani (2002, p. 54) ao afirmar que, "[a]pesar da política de não-valorização do professor, os alunos valorizam muito o papel docente. $\mathrm{O}$ acesso ao conhecimento se faz, principalmente, por meio da relação que estabelecem com o professor".

Por fim, acrescentamos a esta discussão um elemento que, mesmo não estando entre as relações a serem diretamente abordadas neste estudo, pode nos ajudar na tarefa de repensar as relações promovidas pelo estágio. Afinal, estamos aprendendo que é por meio da escuta cuidadosa que novas possibilidades vão desenhando outras formas para o estágio. Principalmente ao acompanhar as apresentações e os momentos de reflexão dos/as licenciandos/as do contexto DF1, foi comum fazerem menção ao conhecimento que constroem quando trabalham com outro/a professor/a licenciando/a, parceiro/a de estágio:

Eu ficava muito assustada com o fato de ter que lecionar. [...] E isso foi algo que eu aprendi a lidar com muita parceria, com muita paciência da minha dupla, me ajudou bastante. (CÍNTIA, PL, DF1)

Eu tinha muito medo de entrar na escola pública por conta de todo esse terror que sempre fazem. [...] A Sheila [parceira de estágio] me ajudou bastante a ter outra visão da sala de aula. (PAOLA, PL, DF1)

Não foi tão ruim quanto eu estava imaginando, mas não foi a melhor experiência do mundo também. Sofri! Fiquei muito feliz de ter duas pessoas do meu lado que eu já conhecia, que eu sabia que podia confiar, contar ali na hora, que eu já conhecia o estilo, então me ajudou demais. Se eu estivesse lá sozinha, não sei como teria sido. [...] (AMANDA A., PL, DF1)

Eu fiquei muito apreensiva, mas a minha dupla ajudou muito. Ela me ajudou bastante, em tudo, no planejamento a gente fazia tudo juntas. Então, eu fui vendo aos poucos que se você se esforçar dá para sair alguma coisa dali. (SARA, PL, DF1)

Outro momento que aprendi foi com a Isabela também. Ela observou as minhas aulas no [nome da escola] e isso foi um dado para o meu TCC. A gente fazia uma sessão reflexiva todos os dias depois das aulas. Então foi aí que ajudou muito na minha prática, sabe? Foi com essa experiência, com essas conversas que eu aprendi. Não com o modelo da universidade que é top-down. (TENNESSEE, PL, GO4) 
Se considerarmos que essas colocações são feitas em contextos de estágio em que estamos ressaltando os entraves causados pelo estabelecimento de relações hierárquicas, características da colonialidade, e pela falta de diálogo, podemos pensar que um ponto importante a ser considerado nas relações entre os/as professores/as licenciandos/as seja uma menor incidência dessa diferença hierárquica. Tennessee (PL, GO4) ressalta ainda que são essas atividades, entre ele e Isabela, que mais o ensinaram e se refere ao modelo da universidade como top-down. A valorização do diálogo, assim como a queixa pelo seu não estabelecimento nas diferentes esferas do estágio, é um ponto recorrente na fala de Tennessee (PL, GO4). Essas colocações contribuem para olharmos decolonialmente para o estágio, considerando outras possibilidades de construção de conhecimento e nos abrindo para novas configurações dessas relações que são ali vivenciadas.

Ainda que os relatos desses/as professores/as licenciandos/as tenham focalizado a importância de contar com a coparticipação de um/a colega, eles/as reiteram que sua presença foi importante para que pudessem lidar com o "susto", o "medo", as “expectativas ruins" ou a "apreensão" que envolvem o estágio. É comum que situações novas gerem ansiedades, principalmente se considerarmos que estamos tratando com jovens que estão iniciando a profissão; no entanto, é importante considerarmos o que Paola (PL, DF1) acrescenta: o medo acontece "por causa desse terror que sempre fazem". Quem faz esse terror? De certa forma, se não problematizamos a situação da escola pública, acabamos por endossar esse "terror". Conforme o relato de Dánie (PU, MT2), alguns tipos de estágio ajudam a reforçar um discurso de fracasso da escola pública. Nesse caso, quanto menos conhecemos a escola, maior o risco de reproduzirmos esse tipo de prática.

Os apontamentos desses/as professores/as licenciando/as corroboram a afirmação de Grosfoguel (2010) de que são outros olhares, ou "margens", que poderão tecer uma crítica à modernidade/colonialidade. E é por meio dessa crítica e do desenvolvimento de um pensamento de fronteira (MIGNOLO, 2009) que poderemos estabelecer projetos mais éticos e diálogos mais horizontais. Seguindo no desafio de entrecruzar esses diferentes olhares acerca das relações interpessoais no estágio, passamos, então, às considerações dos/as professores/as da escola e dos/as professores/as da universidade. 


\subsection{As relações entre os/as professores/as da escola e os/as professores/as da universidade}

Chegamos, então, às problematizações acerca das relações estabelecidas entre professores/as da escola e da universidade. Na medida em que vamos reunindo partes dessas conversas realizadas com pessoas de locais diferentes, engajadas em práticas de ensino particulares, vamos percebendo que, se não acreditamos que o ensino está fortemente ligado à construção dessas relações, elas vão ficando superficiais e em segundo plano. Como pontua Oliveira (2014, p. 160), “[n]ão se trata, portanto, de romantizar essas relações, mas de perceber que nos processos de construção de conhecimento estão em curso, também, processos de construção de sujeitos".

Iniciamos, então, esta discussão com os relatos dos/as professores/as da escola. Em um momento da conversa, eles/as falaram um pouco sobre sua relação com os/as professores/as da universidade:

Nenhuma! Nenhum contato. Nenhuma, com ninguém. [...] Depois a professora me encontrou e agradeceu por eu ter recebido o aluno. [...] Eu não sei como é feita essa supervisão do professor de estágio com o estagiário, mas do professor de estágio com o da rede pública, não existe. (SUZY, PE, GO4)

Eu não tive nenhum contato com a professora de estágio dela [referindo-se a uma professora licencianda]. (LAURA, PE, GO4)

Com a professora da universidade eu não tive contato, nem escrito, nem pessoal, nem por telefone, nada. Eu não tive contato com ela. (KELLY, PE, GO4)

Não, isso eu não tive nenhum contato, com ninguém [da universidade]. Eu só tive contato com ela mesma [professora licencianda]. Ela trazia alguns papéis, algumas entrevistas, [...] mas eu nunca tive oportunidade de conhecer ninguém, não. Pode ser que o professor [da universidade] não foi conversar comigo por confiar nela. (LÚCIA, PE, GO4)

Na verdade, não vi nenhuma professora da universidade. Acredito que, devido ao número de estagiários, não podiam estar presentes em todas as escolas. (MÁRCIO, PE, MT1)

Vemos, nos relatos, que muitos/as professores/as da escola jamais se encontraram com os/as professores/as daqueles/as professores/as licenciandos/as que acompanharam durante o estágio. Além disso, outros/as participantes afirmam que o contato que tiveram com os/as professores/as da universidade foi muito pouco: 
Eu tive só dois momentos em que ele foi à escola conversar, fazer o acompanhamento. A primeira vez, a gente foi sentar para conversar e explicar como é que era o trabalho, de cá e de lá. Como eu fazia e o que eles pretendiam. E uma dessas aulas o professor foi assistir também. Então, eu achei muito pouco, sabe? (JACY, PE, GO4)

Olha, eu tive contato com o professor de estágio do estagiário apenas uma vez. E há pouco tempo ele perguntou pra mim como estava e eu disse: "na verdade não está porque o estagiário não apareceu mais". Nós trocamos alguns e-mails e não apareceu mais. Então, durante a observação do estagiário das minhas aulas eu não tive contato com o professor dele, só posteriormente. (LAVÍNIA, PE, GO4)

É muito diferente da experiência que eu tive, eu sempre me baseio na experiência que eu tive, a minha professora acompanhava a gente. [...] Nunca aconteceu isso com os professores dos estagiários. Ela vai só na primeira semana, apresenta os alunos pra mim, conversa um pouquinho, mas ela nunca entrou em sala. Nunca, nem quando eles estão observando, nem quando estão ministrando. Eu acho isso muito estranho. (BLACK, PE, GO4)

Com base nesses relatos e na discussão realizada, nos questionamos se a prática de estágio, da forma como está sendo conduzida, não estaria contribuindo para um afastamento cada vez maior da universidade em relação à escola e para uma consequente desvalorização dos saberes deste espaço de formação. Conforme temos discutido, essa separação corrobora um projeto de manutenção de colonialidade epistêmica, que privilegia e invisibiliza saberes. Além disso, como já foi dito, esse afastamento torna o estágio uma prática formativa meramente burocrática e pouco significativa para seus/suas participantes.

No que concerne às relações estabelecidas com os/as professores/as da escola, os/as professores/as da universidade reconhecem o distanciamento que existe entre eles/as e demonstram compreender a importância de que esses laços sejam estreitados:

Eu preciso falar porque senão fica parecendo uma coisa vicária, né? Eu não vejo esse personagem, o professor, eu escuto sobre ele, sobre as aulas dele e eu fico pensando: cadê essa pessoa? A voz dessa pessoa. Então ainda tem, eu estou esperando a [nome da outra professora de estágio] melhorar de saúde porque aí ela com a parte tecnológica pra gente criar esse grupo virtual e ver se a gente consegue fazer isso de forma mais sistemática, o professor supervisor participando mais em contato com a [nome da universidade]. (GRACE, PU, GO4)

Eu não chego a ter muito contato com os professores da escola. O contato mesmo é esse diálogo pra receber os estagiários e eu tenho até que pensar numa forma melhor de integrar a universidade e a escola, que, assim que eu terminar o meu doutorado, eu estou pensando em começar e dar continuidade ao programa de formação continuada que a professora [nome] tinha aqui e teve que parar porque ela foi embora. Porque eu acho que nessa formação 
continuada dava pra ter esse diálogo, dava pra fazer esse diálogo legal. E assim que eu terminar o doutorado eu quero voltar com isso. Porque o meu contato com elas é bem pouco e eu vejo que poderia ser melhorado. (SEVERO, PU, GO3)

As passagens ilustram o pouco ou nenhum contato que esses/as professores/as da universidade reconhecem estabelecer com os/as professores/as da escola. A pergunta parece, no entanto, inquietá-los/as já que todos/as apontam possíveis caminhos para que esse contato se estabeleça. A opção apresentada por Grace (PU, GO4) compreende o próprio estágio, com o uso de alguns recursos, como possibilidade de interação. Como discutido, é importante que possamos vislumbrar esse estágio como promotor de um trabalho conjunto da universidade e da escola e, mais importante que isso, que estejamos dispostos/as a ressignificar o tipo de relação hierárquica que tradicionalmente se estabeleceu entre esses dois espaços.

Já para Severo (PU, GO3) esse contato seria melhorado por meio da promoção de formação continuada para os/as professores/as da escola. O trabalho de formação continuada é um importante elo entre a universidade e a escola, e Pimenta e Lima (2012) também advogam por um estágio que possa servir a esse propósito. A nossa ressalva é que, em geral, as situações de formação continuada não ressignificam o papel da universidade nas relações que se constroem com os/as professores/as da escola. A universidade continua sendo a instituição que oferece formação. Ainda não tomamos conhecimento de um curso de formação continuada oferecido pelos/as professores/as da escola para os/as professores/as da universidade. Será que haveria engajamento de nossa parte caso nos fosse dada a oportunidade? O trabalho conjunto durante o estágio nos parece mais propício para o estabelecimento de parcerias e para a promoção de situações que possam promover "um diálogo e uma comunicação verdadeiramente horizontais" (GROSFOGUEL, 2010, p. 483).

\section{Considerações finais}

Nosso principal objetivo neste estudo consiste na problematização das relações interpessoais que são estabelecidas durante o desenvolvimento do estágio. Neste caso, o foco é a formação de professores/as de inglês e as problematizações foram construídas com os/as agentes do estágio: professores/as da escola, professores/as licenciandos/as e 
professores/as da universidade. Fazer esse caminho como um projeto decolonial e enfrentar os desafios que este estudo nos coloca é parte de um exercício crítico que nos impele a acreditar nas possibilidades de desestabilização e na importância dos movimentos de mudança. Além disso, temos o desafio de reconhecer e confrontar os privilégios historicamente conferidos aos saberes da universidade, abrindo espaço para os outros saberes que compõem a formação docente.

Apesar de advogarmos pela ressignificação das relações construídas no estágio, não temos a intenção de dizer que um trabalho inovador e decolonial na formação dependa, unicamente, da iniciativa de professores/as da universidade, da disponibilidade de professores/as da escola e do compromisso de professores/as licenciandos/as. Fazer isso seria desconsiderar todo um contexto histórico e estrutural de desvalorização da educação que interfere diretamente em nossas realidades. Sendo assim, abordar a ressignificação do estágio é também discutir as condições docente e discente e buscar outras possibilidades de atuação.

Além disso, argumentamos que a ressignificação do estágio depende de sua ressignificação epistemológica e de nossa abertura para outras formas de saber, de pensar, de ser e de viver que nos aproxime da escola para a construção de novos conhecimentos. Para isso, é importante reconhecermos a universidade como instituição que, historicamente, reproduz colonialidades, as quais são

[...] mantidas vivas em livros, nos critérios para o desempenho acadêmico, nos padrões culturais, no senso comum, na autoimagem dos povos; em nossas aspirações, e em muitos aspectos de nossa experiência moderna. De certo modo, como sujeitos modernos nós respiramos colonialidade todo o tempo e todos os dias. (GROSFOGUEL, 2013, p. 13)

Se não nos engajamos com questionamentos dessa natureza, acabaremos por reproduzir valores e práticas que são tidos como naturais em nossas vivências e que se apresentam para nós como irremediáveis, imutáveis.

Nesse sentido, o pensamento decolonial nos ajuda a desafiar as hierarquias historicamente estabelecidas entre o conhecimento produzido na escola e na universidade. Ajuda-nos também a reconhecer a necessidade de ressignificar as relações estabelecidas com os/as agentes da escola. Precisamos de abertura para a vivência desse espaço, para a compreensão de suas dinâmicas, para que possamos nos permitir olhar e ouvir de outros ângulos. Talvez assim possamos desenvolver um olhar e uma escuta 
respeitosos, e aprender, valendo-nos de atitudes de engajamento e de solidariedade, com aqueles/as que vivenciam conosco a tarefa de educar.

\section{REFERÊNCIAS}

BORELLI, J. D. V. P. Construindo sentidos sobre o estágio na reflexão com seus agentes. Revista Papéis, n. 43, v. 22, p. 30-50, 2018a. Disponível em: $<$ http://seer.ufms.br/index.php/papeis/article/view/5723/5318>. Acesso em: 20 maio 2019.

BORELLI, J. D. V. P. O estágio e o desafio decolonial: (des)construindo sentidos sobre a formação de professores/as de inglês. 2018b. 224f. Tese (Doutorado em Letras em Linguística) - Universidade Federal de Goiás, Goiânia, 2018a.

CASTRO-GÓMEZ, S. Decolonizar la universidad: la hybris del punto cero y el diálogo de saberes. In: ; GROFÓGUEL, R. (Org.). El giro decolonial: reflexiones para uma diversidad epistémica más allá del capitalismo global. Bogotá: Siglo del Hombre Editores, 2007. p. 79-91.

DENZIN, N. K.; LINCOLN, Y. S. The discipline and practice of qualitative research. In: . (Ed.). The landscape of qualitative research. 4. ed. Thousand Oaks: Sage Publications, 2013. p. 1-41.

FURLANI, L. M. T. A parceria e a aproximação na relação professor-aluno na universidade. In: ALMEIDA, L. R. de; PLACCO, V. M. N. de S. (Org.). As relações interpessoais na formação de professores. São Paulo: Ed. Loyola, 2002. p. 51-64.

GATTI, B. A. A formação inicial de professores para a educação básica: as licenciaturas. Revista USP, n. 100, p. 33-46, dez./jan./fev. 2013-2014. Disponível em: <http://www.revistas.usp.br/revusp/article/view/76164/79909>. Acesso em: 10 fev. 2019.

GROSFOGUEL, R. Para descolonizar os estudos de economia política e os estudos póscoloniais: transmodernidade, pensamento de fronteira e colonialidade global. In: SANTOS, B. S.; MENESES, M. P. (Org.). Epistemologias do sul. São Paulo: Cortez, 2010. p. 455-491.

GROSFOGUEL, R. The structure of knowledge in westernized universities: epistemic racism/sexism and the four genocides/epistemicides of the long $16^{\text {th }}$ century. Human 
Architecture: Journal of the Sociology of Self-knowledge, n. XI, n. 1, p. 73-90, Fall, 2013. Disponível em: http://scholarworks.umb.edu/humanarchitecture/vol11/iss1/8/. Acesso em: 10 fev. 2019.

KERR, J. Western epistemic dominance and colonial structures: considerations for thought and practice in programs of teacher education. Decolonization: Indigeneity, Education \& Society, v. 3, n. 2, 2014, p. 83-104. Disponível em: https://jps.library.utoronto.ca/index.php/des/article/view/21148. Acesso em: $10 \mathrm{fev}$. 2019.

LANDER, E. Ciências sociais: saberes coloniais e eurocêntricos. In: LANDER, Edgardo. (Org.). A colonialidade do saber: eurocentrismo e ciências sociais. Buenos Aires: Conselho Latino-americano de Ciências Sociais - ClACso, 2005. p. 8-20.

LÜDKE, M.; BOING, L. A.; Do trabalho à formação de professores. Cadernos de Pesquisa, v. 42, n. 146, p. 428-451, maio/ago. 2012. Diponível em: http://www.scielo.br/pdf/cp/v42n146/07.pdf. Acesso em: 10 fev. 2019.

MALDONADO-TORRES, N. Sobre la colonialidad del ser: contribuciones al desarrollo de un concepto. In: CASTRO-GÓMEZ, S.; GROFÓGUEL, R. (Org.). El giro decolonial: reflexiones para uma diversidad epistémica más allá del capitalismo global. Bogotá: Siglo del Hombre Editores, 2007. p. 127-167.

MALDONADO-TORRES, N. A topologia do ser e a geopolítica do conhecimento: modernidade, império e colonialidade. In: SANTOS, B. S.; MENESES, M. P. (Org.). Epistemologias do sul. São Paulo: Cortez, 2010. p. 396-443.

MIGNOLO, W. D. Epistemic disobedience, independent thought and de-colonial freedom. Theory, Culture \& Society, Los Angeles, London, New Delhi, Singapore: Sage, v. 26, n. 7-8, p. 1-23, 2009.

Local histories/global designs: coloniality, subaltern knowledges and border thinking. Princeton: Princeton University Press, 2012.

OLIVEIRA, M. G. de. A sala de aula, seus sujeitos e suas relações. In: SOUZA, J. V. A. de; DINIZ, M.; OLIVEIRA, M. G. de. (Org.). Formação de professores(as) e condição docente. Belo Horizonte: Editora UFMG, 2014. p. 155-173. 
PESSOA, R. R.; SILVESTRE, V. P. V.; BORELli, J. D. V. P. Challenges of a decolonial undertaking in teacher education. Calidoscópio, 2019 (no prelo).

PIMENTA, S. G.; LIMA, M. S. L. Estágio e docência. 7. ed. São Paulo: Cortez, 2012.

QUIJANO, A. Colonialidade do poder, eurocentrismo e América Latina. In: LANDER, E. (Org.). A colonialidade do saber: eurocentrismo e ciências sociais. Buenos Aires: Conselho Latino-americano de Ciências Sociais - CLACSO, 2005. p. 107-130.

Colonialidade do poder e classificação social. In: SANTOS, B. S.; MENESES, M. P. (Org.). Epistemologias do sul. São Paulo: Cortez, 2010. p. 84-130.

SILVA, M. da. Desenvolvendo as relações interpessoais no trabalho coletivo de professores. In: ALMEIDA, L. R. de; PLACCO, Vera M. N. de S. (Org.). As relações interpessoais na formação de professores. São Paulo: Ed. Loyola, 2002. p. 79-90.

ZEICHNER, K. M. Repensando as conexões entre a formação na universidade e as experiências de campo na formação de professores em faculdades e universidades. Educação, Santa Maria, v. 35, n. 3, p. 479-504, set./dez. 2010.

WALSH, C. Interculturalidade crítica e pedagogia decolonial: in-surgir, re-existir, reviver. In: CANDAU, V. M. (Org.). Educação intercultural na América Latina: entre concepções, tensões e propostas. Rio de Janeiro: 7 Letras, 2009. p. 12-42. 